\title{
University Makerspaces: Characteristics and Impact on Student Success in Engineering and Engineering Technology Education
}

\author{
Miss Alexandra Longo, American Society for Engineering Education
}

Alexandra (Alex) Longo currently serves as Program Manager of Education and Career Development at ASEE, where she leads the Online Learning initiative, manages externally funded programs and projects, and assists with stakeholder workshop development and implementation. Alex works closely with the ASEE Diversity Committee and the NSF-funded project NSF-funded project Promoting LGBTQ Equality in STEM. Prior to working at ASEE, Alex held positions related to education and events at the Solar Electric Power Association (SEPA) and the Society for Neuroscience (SfN), both in Washington, DC. Alex has a passion for instructional design, informal education, and hands-on learning, and received her MA in Museum Education from Seton Hall University in 2013.

\section{Dr. Brian Yoder, American Society for Engineering Education}

Dr. Yoder is the department director, guiding the overall direction of research and evaluation activities. Prior to working at ASEE, Brian worked at NASA Education, overseeing the development of an on-line performance management system to assess NASA's educational investments nationally. He also serves as President of the Washington Evaluators, a local affiliate of the American Evaluation Association.

\section{Dr. Rocio C. Chavela Guerra, American Society for Engineering Education}

Rocio Chavela is Director of Education and Career Development at the American Society for Engineering Education (ASEE). She holds a Ph.D. in Engineering Education from Purdue University, a B.S. and a M.S. in Chemical Engineering from Universidad de las Americas, Puebla in Mexico. Rocio's current efforts focus on engineering faculty and graduate student development, with particular emphasis on the adoption of evidence-based instructional practices.

\section{Rossen Tsanov, American Society for Engineering Education}




\title{
University Makerspaces: Characteristics and Impact on Student Success in Engineering and Engineering Technology Education
}

\begin{abstract}
With the growth and increased visibility of the Maker Movement, a large number of makerspaces have been established in different venues, including community spaces, museums, and libraries. In the world of academia, makerspaces have multiplied on university and college campuses over the past decade, as spaces for students to enhance their education with creative and experiential learning. Makerspaces, as a supplement to traditional classroom learning, have the capacity to offer educational value to both engineering and engineering technology students. This paper explores how a respondent group of engineering deans and engineering technology deans and department chairs view, implement, and value Making and makerspaces within their academic institutions.

In spring 2016, the American Society for Engineering Education (ASEE) distributed a survey to learn how and to what extent makerspaces are implemented in engineering and engineering technology schools and programs and to assess the perceived value of makerspaces and Making in these settings. The ultimate goal of this survey is to help inform how Making and makerspaces can best be incorporated into engineering and engineering technology education. Findings from this survey indicate that university makerspaces emphasize both education and entrepreneurship in their primary uses, though they may vary in physical characteristics like ownership and operation, size and equipment type and quantity. Regarding impact, survey respondents perceived that Making results in positive outcomes on student-level and university-levels, increasing diversity, access and retention, and to a lesser extent, improving student grades and classroom performance. Engineering deans focused more on university-level impact (including diversity and retention), while engineering technology deans and chairs focused on student-level impact (including performance and grades).
\end{abstract}

\section{Introduction}

\section{The Maker Movement}

Although the term "Making" is credited to the 2005 founding of Make magazine, a formal definition has yet to be established. Instead of defining the concept in set terms, recent sources have characterized it by the many activities that emphasize its creative and experiential aspects, often in the form of action verbs. In a 2014 interview with Phil Larson of the White House Office of Science and Technology, Maker Media CEO Dale Dougherty loosely defined Making as "creating, producing, crafting, shaping, tinkering, composing, and building" (p. 1). In a survey 
of Makers at the 2012 World Maker Faire in New York City, Lande, Jordan and Nelson noted the most frequent verbs used to define Making were "making," "doing," and "creating" (2013). Anderson (2012) asserted that everyone is a Maker, noting activities including gardening, cooking, and scrapbooking. By conducting a thorough review of recent literature on the subject, Martin created a working definition of "Making," as a "class of activities focused on designing, building, modifying, and/or repurposing material objects, for playful or useful ends, oriented towards making a 'product' of some sort that can be used, interacted with, or demonstrated" (2015, p. 31). Those who partake in the act of Making are known as "Makers." As a group, Makers are a growing community of creative individuals who engage in Making activities, representing a wide variety of backgrounds, interests, and levels of expertise. Lande, Jordan, and Nelson (2013) noted that Makers are "thought leaders" and are often defined and identified in the context of the larger Maker Movement.

The birth of the modern Maker Movement can be attributed largely to the recent growth and prevalence of digital culture, along with increased accessibility of electronics, software, hardware, and tools. As noted by Anderson (2012), Bajarin (2014), Evgeny (2014), Martin (2015), and Voigt et al. (2016), these factors transformed consumers into creators. Sources have also acknowledged the catalytic and supportive role that Make magazine and Maker Media have played in the development and growth of the movement. Both Dougherty (2014) and Martin recognized Make magazine as a movement catalyst. A 2011 Economist article noted Make magazine's influence as a "central organ of the movement" (p. 3) and Morozov (2014) described it as a cheerleader for Makers, acknowledging that the "intellectual infrastructure" provided by Maker Media allowed Makers to develop and share their skills and creations (para. 14). One of the main places where Makers can collaborate and share processes and products is a Makerspace. Makerspaces can be located in a wide variety of spaces, including libraries, art galleries, museums, laboratories, and workshops. Although makerspaces can vary greatly, Davee, et. al defined them "fundamentally [as] places to design, explore, and create" (2015, p. 3).

Making gained significant visibility due to President Obama's support for the Maker Movement, culminating in the 2014 White House Maker Faire, a newly established National Week of Making, and the Nation of Makers Initiative. The Nation of Makers Initiative was a call to federal agencies, companies, organizations, and schools to pledge commitments to increase Making opportunities and technologies for students, entrepreneurs, and the general public. Pledges from this initiative showed significant promise for Making and its contributions to science, technology, engineering and mathematics (STEM) subjects, including the National Science Foundation's pledge to invite early concept proposals on STEM-related Making projects and the formation of the MakeSchools Higher Education Alliance, a group of more than 150 academic institutions dedicated to supporting Making on their campuses (The White House, 2014). In the MakeSchools Higher Education Alliance's 2015 report on the state of Making, the three most important factors for creating a Maker culture on campus were listed as: 1) resources 
and environment (e.g. an established Makerspace and a collaborative atmosphere), 2) education and training for both students and faculty, and 3) opportunities for students to showcase their work (p. 13). In academic settings, Making and Makerspaces often embrace the principles of experiential learning.

\section{University Makerspaces}

In academic engineering and engineering technology settings, Making draws many parallels to experiential education, most notably their shared emphasis on both hands-on learning and selfdirected, iterative learning experiences. Experiential education recognizes risk-taking and experimentation beneficial to learning, asserting that these features of the learning process further engage the learner, and allow them to better construct meaning from the experience, resulting in increased creative skill and real-world connections (Association for Experiential Education, 2016). Iterative learning experiences are becoming more common in engineering and engineering technology education, particularly with the spread of university makerspaces. Foster, et. al (2015) noted that design education and active pedagogies help advance engineering education, and Making experiences can increase both knowledge (conceptual, procedural, and analytical) and practical skills. Barret, et. al (2015) reiterated the importance of hands-on learning experiences in engineering education, citing that physical modeling and prototyping in university makerspaces help improve design quality, connect class lessons to real-world issues, and consistent iteration helps both "mitigate design fixation" and "reinforce[s]...adaptive and creative thinking" (p. 2). University makerspaces serve as a central location for students to practice knowledge learned in the classroom, and hone their design skills.

Antonucci-Durgan, et. al (2014), Dukart (2016), and Whitmer (2014) acknowledge academic makerspaces as spaces where experiential education occurs. Two examples of experiential learning opportunities are internships and cooperative learning (co-op) programs. While internships and co-op programs are encouraged in engineering education settings, there are few established opportunities of such opportunities at university makerspaces. There is evidence of several university makerspace internships (including Tulane University and the University of Pennsylvania Libraries), but there is no research on the standards, best practices, and/or effectiveness of university makerspace internships. Research for this paper has resulted in no examples of university makerspace co-op programs. As defined by the University of Houston (2017), "cooperative education...is a type of internship program that enables college students to receive career training with pay as they work with professionals in their major fields of study." Rather than offering cooperative education experiences, makerspaces tend to focus on collaborative experiences, emphasizing knowledge-sharing, co-working, and a strong sense of community. Though the majority university makerspaces, at this time, do not offer explicit internship and/or cooperative (co-op) learning opportunities, the majority offer opportunities for "self-discovery, collaboration, and co-learning" which promote communication and skill 
development; Whitmer (2014) argued that these activities may help "better prepare graduates to enter a world of disruptive change" (p. 3).

The first university makerspace was implemented in 2001 at the Massachusetts Institute of Technology (MIT). As of June 2015, there were 40 university makerspaces in operation, among the U.S News and World Report's 2014 ranking of the top 100 best undergraduate engineering programs (Barrett, et. al, 2015). Though university makerspaces vary in size, location, staffing, and accessibility, there are several characteristics shared by all. Barrett, et. al (2015), Forest, et. al (2014), and Wilczynski (2015) all noted the sense of community embraced by university makerspaces, exhibited by an environment conducive to collaboration between students. There is currently a need for a baseline to study university makerspaces, their best practices, and the specific ways that they can benefit engineering education. Morosz, et. al (2015) posited that Making activities in university makerspaces can improve retention and encourage broader participation in engineering, noting that "there is a strong relationship between the amount of engineering experiences and engineering design self-efficacy," a quality which has been shown to increase retention among underserved groups (p. 3). The survey conducted seeks to further add to the literature on university makerspace promising practices, and gain more information on the specific university-level (student retention, diversity and access) and student-centered (student performance, engagement, and grades) impacts that university makerspaces have on engineering and engineering technology education.

\section{Methodology}

In the spring of 2016, the American Society for Engineering Education (ASEE) distributed an online survey (see Appendix) to engineering deans (ED) and engineering technology deans and department chairs (ETDC). The survey was designed by ASEE's Assessment, Evaluation and Institutional Research (AEIR) department. The survey consisted primarily of a series of openended questions that asked respondents to define Making, asked them to describe Making activities in their university, school, or department, asked how makerspaces are managed at their university, and asked about perceived student outcomes they attribute to Making. Two reminder emails, encouraging recipients to complete the survey, were sent during a two-week period. The surveys were distributed via LISTSERVs managed by ASEE. The individuals who receive notifications from the aforementioned LISTSERVs include 320 ED and 90 ETDC, each of whom oversees at least one ABET accredited undergraduate engineering or engineering technology program and/or a graduate engineering program.

The survey received 93 responses, 64 identified as ED, 13 identified as ETDC, and 16 identified as 'other'. Those who identified as 'other' were forwarded the email from an ED or ETDC and asked to complete the survey. The "other' category includes makerspace directors, associate 
deans, and faculty who are knowledgeable about makerspaces in their universities. To simplify our analysis, we re-coded the 'other' respondents as either affiliated with engineering or engineering technology; this re-coding resulted in 77 responses from engineering and 16 from engineering technology. The response rate to the surveys was 24 percent for ED and 18 percent for ETDC. The survey responses should not be viewed as representative of Making activities for all engineering and engineering technology schools nationally. Results should be seen as examples of engineering and engineering technology schools that have makerspaces, and of the views and opinions of the engineering deans and engineering technology deans and department chairs associated with these schools.

\section{Results}

\section{Defining Making in Engineering and Engineering Technology}

In answering "What does Making mean to you?" the majority of respondents acknowledged the creative and hands-on nature of Making, with 34 respondents using a variation of the word "create" and 31 respondents using a variation of the word "design." About half of the respondents defined Making as an activity that provides the opportunity to design, prototype, test, and/or manufacture artifacts rapidly, and with multiple iterations, while using engineering knowledge, technology, and tools. For both ED and ETDC, Making is about bringing concepts, ideas, and designs to life by converting them to tangible products. Related to this notion is the acknowledgment of the entrepreneurial and innovative nature of Making. Several respondents were careful to note that while Making is entrepreneurial and innovative at heart, there should be a final product that finds a solution or provides some sort of value; one respondent conveyed this succinctly with their response, defining Making as "the capacity to understand and engage from the design-to-deployment-to-sustainability of potential products for society."

To a lesser extent, respondents noted the relationship between Making and education, with 4 respondents citing "education" and 12 respondents citing "learning" in their definitions of the term. Engineering deans were more likely to note the educational characteristics of Making, particularly related to engineering education, than their engineering technology counterparts, who spoke more about Making and its relation to prototyping or design. About one-quarter (19) of engineering deans and one-third (5) of engineering technology deans and chairs noted that they see Making as student-centered, focusing on improving students' creativity, initiative, entrepreneurship, confidence, leadership skills, design ability, hands-on learning experiences, and abstract thought. Several respondents specifically defined Making as "student-driven" or "student self-directed." Though few respondents specifically related Making to engineering careers, Making experiences that emphasize hands-on learning, entrepreneurship, and innovative thinking may improve skills and qualities that make students more employable for positions in 
both academia and industry. Particularly for engineering technology, hands-on learning experiences like Making offer benefits that classroom learning cannot; one respondent stated that "[educators] teach students the theory and design, but without implementing (making) the designs the students are not ready to practice as engineers." The skills improved by Making are comparable to those identified as attributes of "The Engineer of 2020" (National Academy of Engineering, 2004). The National Academies report notes that Engineer of 2020 will be creative, "exhibit practical ingenuity" in addressing and solving complex real-world problems, and possess "dynamism, agility, resilience, and flexibility" to compete and succeed in the everchanging world (p. 55-6).

\section{Characteristics of Engineering and Engineering Technology Makerspaces}

The majority of survey respondents (75\%) indicated that their university, school, or department has a makerspace or multiple makerspaces. More than half of the respondents, the majority of which were engineering deans (ED), indicated that these makerspaces are "distributed," meaning they do not have one central, fixed location, but rather occupy several spaces on campus. In some cases, one makerspace serves as a central location, while others act as nodes, complementing and supplementing the main space. In other cases, the makerspaces are associated with different departments and do not work as a cohesive unit. The remainder of respondents indicated that they possess a "dedicated" makerspace, which means it exists and operates in a single, fixed location, with all necessary tools and equipment onsite. More information on makerspace types and characteristics can be found in the 2015 Maker Educational Initiative report entitled Makerspaces: Highlights of Select Literature.

Respondents were asked more in-depth questions about the physical aspects of these spaces, first regarding ownership and operation (i.e., "Who owns and operates this Makerspace?"). This was an open-ended question and received 71 responses in total. Of these respondents, the largest percentage $(33 \%)$ indicated that the makerspace in question is owned and operated by the engineering school/college. The second largest percentage of respondents (31\%) noted university-level ownership and operation. A significant percentage of respondents (18\%) acknowledged that there are multiple makerspaces at their college or university. These makerspaces are often owned by different departments (e.g. Industrial Studies, Architecture, Life Sciences and Agriculture), and operation may vary between departmental/university staff and students.

An interesting finding related to ownership and operation is the mention of collaboration and cooperation, seen in 5 responses. Three out of five of these responses acknowledged current collaboration between departments or entities (e.g. working with the university library) in operation and ownership of the makerspace. Two out of five of these responses mentioned their desire for cooperation and collaboration in the future. One respondent noted that while their 
makerspace is operated by the engineering department, they "desire to operate it in coordination with [the] Undergraduate Research Institute." Another respondent noted that current makerspace ownership varies, but there is work being done "to ensure cooperativity across all labs." Though collaboration was mentioned by few respondents, it is important to note, as this feature is intrinsic to Making, regarding both the willingness to work with others, and the combining of disciplines and subjects.

When asked "Who can access the makerspace?" the majority of respondents indicated that the space can be accessed by all students, regardless of discipline. A number of respondents noted the importance of training and safety guidelines prior to working in the makerspace. Only 9 out of 71 total respondents indicated that the makerspace were accessible to only engineering students. The cross-disciplinary nature and openness of the majority of these makerspaces reinforces the collaborative quality of Making.

\section{Education and Entrepreneurship within the Makerspace}

Though academic makerspaces are located on university and college campuses, their focus may not be solely educational. When asked to describe their makerspace and how it is used, a total of 70 individuals (61 ED and 9 ETDC) provided open-ended responses. Of these respondents, approximately two-thirds of ED and all ETDC shared that their makerspaces serve primarily educational objectives. Respondents shared a variety of educational uses for these spaces; some are used to support classes and individual student projects (including capstone projects and independent study projects), while others are used as a direct supplement to curricula (one respondent noted that their makerspace is used for a required course for all introductory engineering students).

Aside from a solely educational focus (in that the makerspaces uses and activities primarily support curricular activities), a significant number of university makerspaces focus on entrepreneurship and innovation activities, which help prepare students for future careers. Fifteen of 70 respondents (14 ED and 1 ETDC), noted a variation of the terms innovation, invention, and/or entrepreneurship when asked to describe their makerspace and how it is used. An emphasis on entrepreneurship and innovation, as opposed to curricular projects and activities, allows students to "unleash their creative potential," in the words of one respondent. When not limited to curricular activities, students are better able to "explore their ideas" freely.

The entrepreneurship and innovation activities in these makerspaces are tied closely with the practice of design and prototyping. Fifteen of 70 respondents (14 ED and 1 ETDC) specifically mentioned prototyping in their description of their makerspace and its use. Prototyping is an active process where students can, in the words of one respondent, "build, invent and test [their] own creations" using a variety of tools, including 3D printing equipment, fabrication tools, 
computer software, automatic and robotic systems, and other laboratory equipment and materials. Forest, et al. (2014) notes that prototyping and physical modeling allow the designer to better visualize concepts and design attributes, "help[ing] designers identify and rectify problems with their designs before production and eliminate some of the inefficiencies" (p. 5).

A number of survey respondents emphasized the connection between prototyping and entrepreneurship and innovation in their answers. One responded shared that their makerspace allowed "entrepreneurial students to gather to unleash their creative potential by facilitating ideation, prototyping their ideas and ultimately collaborating on technology start-ups." Several advanced university makerspaces operate in conjunction with industry or government agencies to support high-level prototyping, manufacturing and entrepreneurship. By practicing prototyping and hands-on design, and experiencing the entrepreneurial process in a supportive environment, students may be increasing their employability in the engineering industry. One respondent shared that their makerspace offered training for students to advance from low-resolution prototyping to more advanced spaces and equipment. As noted by Forest, et. al., prototyping has both cognitive and practical benefits. Cognitively, it has been shown to help designers make designs of higher quality. In a practical sense, which translates directly to industry employability, prototyping and physical modeling can help minimize risk, by allowing designers to "iterate and improve upon their designs in an informed way while minimizing costs associated with product development and production" (2014, p. 5).

Many of the makerspaces described offer opportunities for both education and entrepreneurship. For instance, these spaces will offer support for curricula and student projects, but also offer space and opportunities for extracurricular learning and Making. These extracurricular activities, as shared by respondents, include student competitions, tinkering and informal designing, hacking, hobbyist exploration, and student-focused social events (like make-a-thons and hack-athons). Several survey respondents specifically noted experiential education components in their makerspaces and larger engineering programs. Experiential learning/education was mentioned by 7 separate respondents throughout the survey. One ED noted that their institution has "experiential tracks" in all of their undergraduate programs. Another ED stated that "more than 50 percent of the courses have experiential learning component[s] and their university makerspace specifically uses experiential learning opportunities to attract more diverse participants. Five separate respondents mentioned internships and co-op learning as part of their makerspace offerings, ranging from required co-op projects to summer internships. One ED responded noted a particularly unique internship opportunity:

A consulting engineer in the community came to [our makerspace] and asked if we could translate paper plans for an environmental site requiring decommissioning. We linked that person with a sophomore student to do the SolidWorks files and suggested [to the engineer that] they might want to do a $3 D$ printed model that would allow them to 'war 
game' how the site would be dismantled. They hired the student who is doing this project for internship credit, has printed and laser cut a very high fidelity model and is now working on writing instructions based on what has been learned from this effort.

In all cases, the use of the makerspace is free of charge for students. Nine respondents ( $7 \mathrm{ED}$ and 2 ETDC) reported that their makerspaces are open to the community at large, for exploration and entrepreneurship projects, with the majority of schools offering this community access free of charge. One ED shared that although the makerspace is not open to members of the community, many of the undergraduate and graduate engineering projects hosted in the space are designed to provide value to the local community. Though the makerspaces, as reported by ED and ETDC, ranged in size (from basement studios and small labs to 60,000 square foot facilities) and equipment (with some makerspaces owning more than $903 \mathrm{D}$ printers and offering specialized manufacturing and construction shops), they all seek to offer opportunities for students to engage in project-based learning and entrepreneurship and innovation, whether these experiences are curricular or extracurricular in nature.

\section{The Impact of Making on Student Success}

Though 76\% percent of respondents indicated that they have a makerspace at their institution, a slightly higher percentage (78\%) reported that their school or department uses Making in their curriculum. Related to this question, survey recipients were asked whether they observed positive student outcomes that they attribute to the incorporation of Making at their school or department. Through their answer selections, respondents indicated that Making has had both broad (college or university level) and personal (individual and unique to the student) impacts on students at their institutions. Regarding broader, practical outcomes, more than $30 \%$ of all respondents believe that Making has helped make engineering more attractive to diverse students and more than $25 \%$ believe that Making has increased student retention. A significant percentage of both of ED and ETDC acknowledged the impact of Making on attracting diverse students (60\% of ED and 47\% of ETDC). A larger percentage of ED than ETDC reported noticing an increase in student retention, with more than half of ED respondents reporting an increase, compared to only about one-third of ETDC.

Later in the survey, respondents were asked to provide examples from their school or department of how Making has increased access to engineering and engineering technology. Respondents indicated a variety in interpretation of the word access; while some related this term to issues of diversity and inclusion, more focused on access within the university space (e.g. offering access to students from different departments and majors). Related to diversity and inclusion, one respondent reported a significant increase in female enrollment in engineering due to Making activities. Another shared that a program associated with their makerspace has "provided significant increases" to student access, "helping to triple the number of underrepresented 
minority students in [the] college." In terms of increasing access within the university, three respondents shared that their makerspaces often serve as locations for events or meetings held by various student groups and clubs, which help to attract students from different majors to the space. Four respondents reported that they use Making as a recruitment tool for high school students to enter undergraduate engineering programs; one shared that their school "work[s] very closely with high schools to encourage students to pursue engineering by offering [an introductory engineering] course to high school students for college credit." Another respondent reported that "enrollments have mushroomed in the last few years, in part due to the growth of the Maker Movement." For those already enrolled in the college, but unsure of their pathway to a career in engineering, Making and makerspaces can offer the opportunity to learn more about other engineering disciplines, as noted by several respondents. By engaging with Making, one respondent recognized that "students are more interested in joining engineering project teams earlier in their studies."

A smaller percentage of survey respondents reported positive individual student outcomes that they attributed to Making. Slightly more than one-quarter of respondents reported improved student performance in the classroom, while only about $15 \%$ reported improved grades. A larger percentage of ETDC (more than 60\%) attribute improved student performance in the classroom to making than ED (45\%). A similar percentage of ETDC and ED attributed Making to the improvement of student grades (31\% and $30 \%$, respectively).

Though this percentage was fairly low, when asked for an example of how Making has increased student engagement, we received 41 write-in responses that speak to the impacts of Making on student success, not only student engagement, but creativity, innovation, and innovative mindset. Several respondents shared that they collaborate externally to encourage student engagement, with industry executives, community leaders, local businesses, and community members in need.

In our sophomore design class, students prototype a "bicycle" for a local person with mobility limitations. This involves considerable making, and students report significant engagement with this project, leading to greater connection to the Engineering program.

Other examples (12 in total, from 9 ED and 3 ETDC) emphasized a focus on increasing student initiative, innovation, and entrepreneurial mindset, with several respondents offering competitions, internships, and opportunities for partnerships with industry representatives. One respondent shared the experience of a student, who launched an NGO based on his involvement with the university's Maker ecosystem:

One student...was less than excited by his experiences in engineering physics. After an experience with Engineers without Borders, identifying the problem that 2 billion people on our planet do not have access to clean light, but rather burn dung or kerosene for 
light, [he] completely changed his undergraduate curriculum and refocussed [sic] it on making and solving this problem. Being involved in our courses, programs, and making ecosystem, [he] launched [an NGO] upon graduation and has delivered over 2 million solar-charged LED lanturns [sic] to communities in India and Africa, and empowered thousands of entrepreneurs to sell, rent, and support the explosive industry he created, that of clean, accessible light in the developing world.

From these write-in responses, it can be concluded that Making does have a positive impact on student success in both engineering and engineering technology, by increasing confidence, creativity, initiative and/or entrepreneurial thinking. In this sense, "success" should be thought of in broad terms, and not be limited to increased performance and/or grades, though these are indeed valid means to assess learning and success. As university makerspaces are still a relatively new phenomenon, there is yet to be an established framework for assessing or evaluating the impact of Making on students. A 2016 ASEE report noted that Makers in educational settings (both formal and informal) have acknowledged this challenge and suggested pursuing more organic types of evaluation that address both short-term and long-term learning outcomes, including the development of practical skills and changes in attitudes and behaviors (p. 2). It should be noted that one respondent specifically mentioned assessing long-term impact from Makerspace learning, through the act of conducting senior exist interview. There may be more universities that practice this process, through senior capstone projects or similar methods that evaluate cumulative or long-term learning impacts. Only one respondent specifically mentioned the assessment of long-term impact (through conducting senior exit interviews), but it's likely that more practice this process (through senior capstone projects and other similar methods).

An interesting result of this survey was the difference between engineering deans (ED) and engineering technology deans and chairs (ETDC) when asked about the impact of Making at both the student and university level. While both groups acknowledged impact on attracting diverse students and promoting student retention, the fraction of positive responses was higher amongst the ED respondents. Regarding diversity, over $60 \%$ of ED noted a positive impact, compared to $45 \%$ of ETDC. The difference was more pronounced regarding retention, with over half of ED noting a positive impact, compared to only one-third of ETDC. This disparity may be related to the specific roles of deans versus those of department chairs, and the recent increased responsibility for engineering deans to increase retention and diversity within their schools.

At the student level, a similar percentage of ED and ETDC (about 30\%) attributed Making to the improvement of student grades, but significantly more ETDC attributed Making to improved student performance in the classroom (more than $60 \%$ compared to $45 \%$ of ED). This may be due to the fact that engineering technology emphasizes the importance of application of knowledge, often through hands-on engineering design experiences. Engineering tends to focus 
more on theory and methods than hands-on application. As Making is intrinsically hands-on, it makes sense that Making experiences would have a stronger impact on classroom performance in engineering technology classes (as opposed to engineering classes). Though the survey did not provide an opportunity for respondents to elaborate on how Making improved student performance in the classroom, ETDC responses from other questions speak to the importance of hands-on experiences in engineering technology. Of the 11 ETDC who provided examples of how Making is used in their curriculum, eight mentioned hands-on learning, prototyping, design, and/or project-based learning (PBL). The three ETDC who did not use these specific terms spoke about specific projects (both independent and team-based) that occur within the university makerspace.

\section{Conclusions and Implications for Further Study}

Findings from this survey indicate several things about university makerspaces and the impact of Making on engineering and engineering technology education. While engineering and engineering technology university makerspaces may vary in physical characteristics (primarily in terms of ownership and operation, size, and type and quantity of available equipment), the majority are accessible to all students, regardless of major, and emphasize both education and entrepreneurship in their primary uses and activities. Survey responses indicated that Making has a positive impact on both a student and university-level, attributing to an increase in diversity, access and retention, and to a lesser extent, increase in student performance and grades. Responses also indicated that Making positively impacts recruitment and student characteristics including creativity, confidence, initiative and innovative thinking. Engineering deans focused more on university-level impact (including diversity and retention), while engineering technology deans and chairs focused more on student-level impact (including performance and grades.

While this survey offers insightful findings into engineering and engineering technology university makerspaces, and the impact that Making can have on both student and university success, there remains to be a current baseline by which to study university makerspaces. Similarly, there is a need for promising practices and evaluation and assessment tools to study the impact of Making in educational settings, particularly those that address both short and long term impacts. Future research should seek to engage a broader respondent group and include opportunities for assessing impact and outcomes in the longer term, through follow-up interviews or focus groups. 


\section{Acknowledgements}

This paper is based upon work supported by the National Science Foundation under grant ECC-155262. The authors gratefully acknowledge all the individuals who contributed to this project, most importantly the engineering deans and engineering technology deans and chairs who completed this survey and offered the thoughtful responses that greatly helped to inform this paper. 


\section{References}

American Society for Engineering Education. (2016). Envisioning the Future of the Maker Movement: Summit Report. Washington, DC: American Society for Engineering Education.

American Society for Engineering Education. (2012). Going the Distance: Best Practices and Strategies for Retaining Engineering, Engineering Technology and Computing Students. Washington, DC: American Society for Engineering Education.

Anderson, C. (2012). Makers: The New Industrial Revolution. New York, NY: Crown Business.

Antonucci-Durgan, D., Wood, S., Turano, P., Hahn, T., Hassildine, E., \& Vogel, D. (2014 Creating Mobile "Makerspaces" to Support Experiential Learning. State University of New York (SUNY). Retrieved from https://dspace.sunyconnect.suny.edu/handle/1951/68231.

Bajarin, T. (2014, May 19). Making It. TIME. Retrieved from http://time.com/104210/maker-faire-maker-movement/.

Barrett, T. W., \& Pizzico, M. C., \& Levy, B., \& Nagel, R. L., \& Linsey, J. S., \& Talley, K. G., \& Forest, C. R., \& Newstetter, W. C. (2015, June). A Review of University Maker Spaces. Paper presented at 2015 ASEE Annual Conference \& Exposition, Seattle, Washington.

Byrne, D., \& Davidson, C. (2015). MakeSchools Higher Education Alliance: State of Making Report. Pittsburgh, PA: Carnegie Mellon University.

Davee, S., Regalla, L., \& Chang, S. (2015). Makerspaces: Highlights of Select Literature. Maker Educational Initiative.

Dougherty, D. (2014, June 13). 5 Questions on "Making" and the White House Maker Faire [Interview by P. Larson]. Retrieved from https://www.whitehouse.gov/blog/2014/06/13/5-questions-making-and-white-housemaker-faire.

Dukart, Kyle. (2016). Educating the New-Century Engineer: Understanding the Role of Extracurricular Project-Based Experiential Learning in Engineering Education. Retrieved from the University of Minnesota Digital Conservancy, http://hdl.handle.net/11299/182258. 
Forest, C. R., Moore, R.A., Jariwala, A.S., Fasse, B.B., Linsey, J., Newstetter, W., Ngo, P., Quintero, C. (2014, Summer). The Invention Studio: A University Maker Space and Culture. Advances in Engineering Education, 4(2), 1-32.

Foster, C. H., \& Dickens, M., \& Jordan, S. S., \& Lande, M. (2015, June). Learning from Toy Makers in the Field to Inform Teaching Engineering Design in the Classroom. Paper presented at 2015 ASEE Annual Conference \& Exposition, Seattle, Washington.

Knight, D.W., \& Carlson, L.E., \& Sullivan, J.F. (2007, June). Improving Engineering Student Retention through Hands-On, Team Based, First-Year Design Projects. Paper presented at 2007 International Conference on Research in Engineering Education, Honolulu, Hawaii.

Lande, M., \& Jordan, S. S., \& Nelson, J. (2013, June). Defining Makers Making: Emergent Practice and Emergent Meanings. Paper presented at 2013 ASEE Annual Conference \& Exposition, Atlanta, Georgia.

Martin, L. (2015). The Promise of the Maker Movement for Education. Journal of Pre-College Engineering Education Research (J-PEER), 5(1), 30-39.

More than just digital quilting. (2011, December 3). The Economist.

Retrieved November 30, 2016, from http://www.economist.com/node/21540392.

Morocz, R. J., Levy, B. D., Forest, C. R., Nagel, R. L., Newstetter, W. C., Talley, K. G., \& Linsey, J. S. (2015). University Maker Spaces: Discovery, Optimization and Measurement of Impacts. Paper presented at the 122nd ASEE Annual Conference and Exposition, Seattle.

Morozov, E. (2014, January 13). Making It. The New Yorker. Retrieved from http://www.newyorker.com/magazine/2014/01/13/making-it-2.

National Academy of Engineering. (2004). Chapter 4: Attributes of Engineers in 2020. The Engineer of 2020: Visions of Engineering in the New Century: National Academies Press.

Voigt, C., Montero, C. S., \& Menichinelli, M. (2016). An empirically informed taxonomy for the Maker Movement. Paper presented at the 3rd International Conference on Internet Science, Florence, Italy. 
What is Co-operative Education (Co-op)? University of Houston Cullen College of Engineering: Engineering Career Center (2017). Retrieved from http://career.egr.uh.edu/students/coop.

What is Experiential Education? (2016). Association for Experiential Education. Retrieved from http://www.aee.org/what-is-ee.

The White House, Executive Office of the President. (2014, June). Building a Nation of Makers: Universities and Colleges Pledge to Expand Opportunities to Make [Press release]. The White House. Retrieved from https://www.whitehouse.gov/sites/default/files/microsites/ostp/building_a_nation_of_ma kers.pdf.

Whitmer, S. (2014). Innovation through Experiential Learning: An Exploration of Maker, Hacker, and Coworking Spaces (Research Excerpt). Retrieved from http://pkallsc.org/assets/files/Innovation_through_Experiential_Learning-1.pdf

Wilczynski, V. (2015, June). Academic Maker Spaces and Engineering Design. Paper presented at 2015 ASEE Annual Conference \& Exposition, Seattle, Washington. 


\section{Appendix}

Maker Survey for Engineering Deans and Engineering Technology Deans / Chairs

1. Which best describes you?

- Engineering Dean

- Engineering Technology Dean or Chair

- Other

2. What does making mean to you? [open-ended]

3. Do you already have activities in your program that could classify as making (i.e. projectbased learning, prototyping)? If so, please describe. [open-ended]

4. Does your university, school, or department have a Makerspace?

- Yes

i. Who owns and operates this Makerspace? (i.e. Department? School? Class?) [open-ended]

ii. Who can access the Makerspace? [open-ended]

iii. Is it located in one static space or is it distributed across campus? [openended]

iv. Please describe the Makerspace and how it is used? [open-ended]

- $\quad$ No [Survey proceeds to next question]

5. Have your observed positive student outcomes that you attribute to the incorporation of making at your school or department? Check all that apply.

- Increased student retention

- Improved student performance in classroom

- Improved grades

- $\quad$ Engineering more attractive to diverse students

6. Does your school or department use making in its curriculum?

- Yes

i. Please describe [open-ended]

- $\quad$ No [Survey proceeds to next question]

7. Do you have an example from your school or department of how making has increased student engagement or access to engineering or engineering technology?

- Yes

i. Please describe [open-ended] 
- No [End of survey] 